Provided for non-commercial research and education use. Not for reproduction, distribution or commercial use.

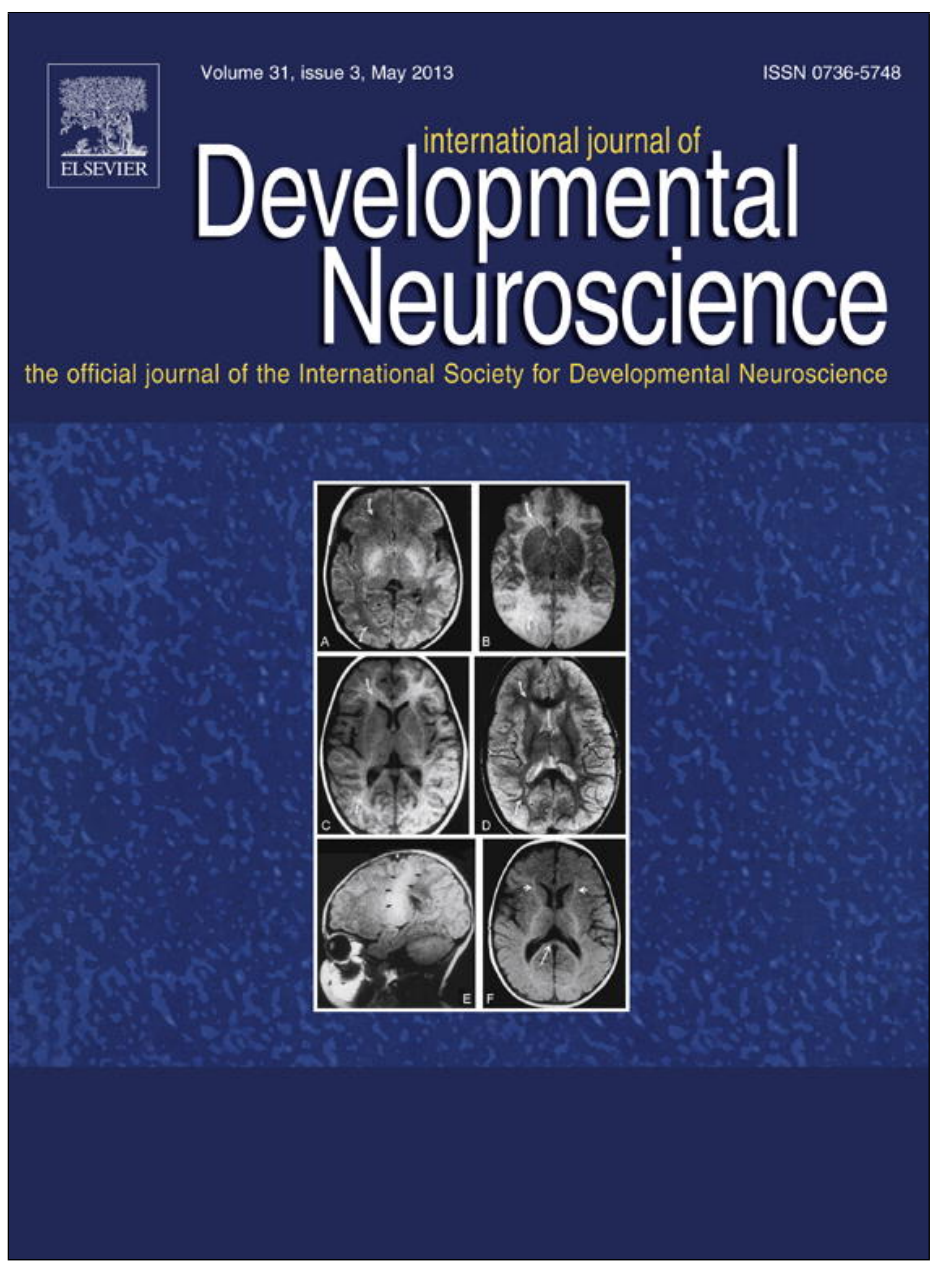

This article appeared in a journal published by Elsevier. The attached copy is furnished to the author for internal non-commercial research and education use, including for instruction at the authors institution and sharing with colleagues.

Other uses, including reproduction and distribution, or selling or licensing copies, or posting to personal, institutional or third party websites are prohibited.

In most cases authors are permitted to post their version of the article (e.g. in Word or Tex form) to their personal website or institutional repository. Authors requiring further information regarding Elsevier's archiving and manuscript policies are encouraged to visit:

http://www.elsevier.com/copyright 


\title{
Gestational protein restriction induces CA3 dendritic atrophy in dorsal hippocampal neurons but does not alter learning and memory performance in adult offspring
}

\author{
A. Lopes ${ }^{a}$, D.B. Torres ${ }^{\text {a }}$, A.J. Rodrigues ${ }^{c, d}$, J.J. Cerqueira ${ }^{c, d}$, J.M. Pêgo $^{c, d}$, N. Sousa ${ }^{c, d}$, \\ J.A.R. Gontijo ${ }^{\text {b }}$, P.A. Boer ${ }^{\mathrm{a}, *}$ \\ a Fetal Programming Laboratory, Department of Morphology of Biosciences Institute, São Paulo State University, Botucatu, SP, Brazil \\ ${ }^{\mathrm{b}}$ Hydro-saline Metabolism Laboratory, Nucleus of Medicine and Experimental Surgery, Department of Medicine Clinic, School of Medical Sciences, University of Campinas, Campinas, \\ SP, Brazil \\ ${ }^{\mathrm{c}}$ Life and Health Sciences Research Institute, School of Health Sciences, University of Minho, Braga, Portugal \\ d ICVS/3B's-PT Government Associate Laboratory, Braga/Guimarães, Portugal
}

\section{A R T I C L E I N F O}

\section{Article history:}

Received 13 December 2012

Accepted 14 December 2012

\section{Keywords:}

Fetal programming

Hippocampus

Dendritic remodeling

Behavior

Protein restriction

\begin{abstract}
A B S T R A C T
Studies have demonstrated that nutrient deficiency during pregnancy or in early postnatal life results in structural abnormalities in the offspring hippocampus and in cognitive impairment. In an attempt to analyze whether gestational protein restriction might induce learning and memory impairments associated with structural changes in the hippocampus, we carried out a detailed morphometric analysis of the hippocampus of male adult rats together with the behavioral characterization of these animals in the Morris water maze (MWM). Our results demonstrate that gestational protein restriction leads to a decrease in total basal dendritic length and in the number of intersections of CA3 pyramidal neurons whereas the cytoarchitecture of CA1 and dentate gyrus remained unchanged. Despite presenting significant structural rearrangements, we did not observe impairments in the MWM test. Considering the clear dissociation between the behavioral profile and the hippocampus neuronal changes, the functional significance of dendritic remodeling in fetal processing remains undisclosed.
\end{abstract}

C 2012 ISDN. Published by Elsevier Ltd. All rights reserved.

\section{Introduction}

A growing body of evidence supports the hypothesis that disturbances during critical periods of fetal development may determinate permanent structural and functional alterations in organs and systems and predispose individuals to metabolic, endocrine, and cardiovascular diseases later in life (Ashton, 2000; Barker, 1998; Lesage et al., 2006; O’Regan et al., 2004; Plagemann, 2004; Seckl and Meaney, 2004). Gestational psychological and nutritional stresses may be involved in fetal programming as shown in several experimental models (Persson and Jansson, 1992; Woodall et al., 1996; Godfrey et al., 1996; Langley-Evans et al., 1996; Mesquita et al., 2010a,b).

Although the underlying mechanisms are still unclear, the association between maternal undernutrition and hormonal dysfunction has been proposed to induce intrauterine fetal

\footnotetext{
* Corresponding author at: Department of Morphology, Botucatu Bioscience Institute, UNESP- São Paulo State University, 18600-000 Botucatu, SP, Brazil. Tel.: +55 1438116264 R118; fax: +55 1935217414 .

E-mail address: alineboer@yahoo.com.br (P.A. Boer).
}

programming. Studies have shown that excessive levels of fetal glucocorticoids may impair brain development, affect behavior and delay cognitive and intellectual functions later in life both in humans and animal models (Johnson et al., 1981; Uno et al., 1990, 1994; Szuran et al., 2000; Antonow-Schlorke et al., 2001; Matthews, 2001; Antonow-Schlorke et al., 2003; French et al., 2004; Karemaker et al., 2008; Weinstock, 2008; Seckl, 2008; de Lima et al., 2012).

It is also known that the hippocampus is a brain area crucial for learning, it memorizes processes and has synaptic plasticity, but the details of this fine modulation are not completely understood. The hippocampus is a brain structure that is related to emotion, memory and spatial learning (Bannerman et al., 2004). This structure is divided into two parts: the ventral hippocampus ( $\mathrm{VH})$ and the dorsal hippocampus (DH), and this separation is made in accordance with the functionality described in the literature (Fanselow and Dong, 2010). In information processing, DH is primarily involved in the cognitive process of learning and memory associated with navigation, exploration, and locomotion, whereas $\mathrm{VH}$ is the part of the temporal lobe associated with motivational and emotional behavior (Fanselow and Dong, 2010). Particularly, studies suggest that the CA3 region of DH mediates the acquisition and encoding of spatial 
information within short-term memory with duration of seconds and minutes. Also, CA3 mediates encoding of information requiring multiple trials to construct relational representations. It should be noted that spatial information represents the critical attribute or domain that is processed in CA3 (Kesner, 2007). It might also be observed, that neuroanatomical studies that have investigated the effects of prenatal malnutrition have found deficits, such as loss of neurons (Lister et al., 2005) decrease of body size, length of apical dendrites and branching and spine density in the CA3 pyramidal cells layer (Diáz-Cintra et al., 1991). Regarding the cellular and molecular mechanisms underlying structural remodeling in the hippocampus, the role of adrenal steroids appears to be most crucial (McEwen, 1999), since repeated corticosterone administration induces retraction of apical dendrites in the CA3 sub region of the hippocampus in adult male rats.

Considering the paucity of evidence, in the present study, we aim to analyze the effects of gestational protein restriction on learning and memory functions and correlate these with the cytoarchitecture of the dorsal hippocampus of adult male rats. The CA3 pyramidal cells were selected because they are an essential link in the DH trisynaptic circuit. Furthermore, as stated above, the DH function has been implicated as substrate for learning and spatial memory.

\section{Experimental procedures}

\subsection{Animals}

The experiments were conducted on age-matched, male offspring of siblingmated Wistar Hannover rats (250-300 g) allowed free access to water and normal rat chow. The general guidelines established by the Brazilian College of Anima Experimentation (COBEA) were followed throughout the investigation. Our local colonies originated from a breeding stock supplied by CEMIB/Unicamp, Campinas, SP, Brazil. Immediately after weaning at 3 weeks of age, animals were maintained under controlled temperature $\left(25^{\circ} \mathrm{C}\right)$ and lighting conditions $(0700 \mathrm{~h}-1900 \mathrm{~h})$, with free access to tap water and standard rodent laboratory chow (Nuvital, Curitiba, PR Brazil) and followed up to 12 weeks of age. The dams were maintained on isocaloric standard rodent laboratory chow with normal protein content [NP] (17\% protein) or low protein content [LP] (6\% protein) ad libitum intake throughout the entire pregnancy. The day that sperm were seen in the vaginal smear was designated as day 1 of pregnancy. All groups returned to the NP chow intake after delivery. Food consumption was determined every day (subsequently normalized for body weight), and body weight was recorded once a week. The male pups were weighted and the ano-genital distance (AGD) was measured. These animals were followed and maintained with normal chow until 16 weeks old. Rats from the NP ( $n=9$ rats from different mothers) and LP ( $n=9$ rats from different mothers) groups were used for behavioral analysis. Following the behavioral tests, the animals were deeply anaesthetized with a mixture of ketamine $(75 \mathrm{mg} / \mathrm{kg}$ body weight, i.p.) and xylasine $(10 \mathrm{mg} / \mathrm{kg}$ body weight, i.p.) and the monitoring of the corneal reflex controlled the level of anesthesia. The rats were perfused transcardially with either saline containing heparin (5\%) for $15 \mathrm{~min}$, under constant pressure, followed by $0.1 \mathrm{M}$ phosphate buffer (PB; pH 7.4) containing 4\% (w/v) paraformaldehyde, or saline for Golgi-Cox staining.

\subsection{Behavioral analysis}

\subsubsection{Morris water maze (MWM)}

Possibly the most widely used test of spatial learning in rats is the Morris wate maze test (Morris, 1984). The whole cognitive performance test was performed and analyzed in a blinded fashion for different trained observers. Behavioral tests were conducted in a circular black tank $(170 \mathrm{~cm}$ diameter) filled to a depth of $31 \mathrm{~cm}$ (at $22^{\circ} \mathrm{C}$ ) and placed in a dimly lit room with extrinsic clues. The tank was divided into imaginary quadrants and had a black platform $(12 \mathrm{~cm}$ diameter, $30 \mathrm{~cm}$ height placed in one of them.

2.2.1.1. Working memory task. We used the test described by Kesner et al. (2000) as a test of PFC function: its goal is to assess the ability of rats to learn the position of the hidden platform and to keep this information on-line during four consecutive trials. The working memory test consisted of $4 \mathrm{~d}$ of acquisition ( 4 trials/day). One each trial day, the position of the platform was kept constant, but the position was varied on each successive day such that all four quadrants were used. Rats were placed, facing the wall of the maze, at a different starting point north $(N)$, east $(E)$, south $(S)$ or west $(\mathrm{W})$ at the start of each of the four daily trials. A trial was considered ended when the rat escaped onto the platform; when this escape failed to occur within $120 \mathrm{~s}$, the animal was gently guided to the platform, and an escape latency of $120 \mathrm{~s}$ was recorded for that trial. Rats were allowed to spend $30 \mathrm{~s}$ on the escape platform before being positioned at a new starting point. The time (in seconds) spent to reach the platform (escape latency) was recorded in the consecutive trials.

2.2.1.2. Reference memory task. The reference memory test was described by Morris (1984) and assesses the function of the hippocampus: its goal is to assess the ability of rats to learn the position of the hidden platform and to keep this information during all test days. The test consisted of $4 \mathrm{~d}$ of acquisition ( 4 trials/day). During the four days the platform remained in the same quadrant. Rats were placed, facing the wall of the maze, at a different starting point north $(\mathrm{N})$, east $(\mathrm{E})$, south $(\mathrm{S})$ or west $(\mathrm{W})$ at the start of each of the four daily trials. A trial was considered ended when the rat escaped onto the platform; when this escape failed to occur within $120 \mathrm{~s}$, the animal was gently guided to the platform, and an escape latency of $120 \mathrm{~s}$ was recorded for that trial. Rats were allowed to spend $30 \mathrm{~s}$ on the escape platform before being positioned at a new starting point. The time (in seconds) spent to reach the platform (escape latency) were recorded in the consecutive trials

\subsection{Histological procedures}

Whole brains were collected from NP and LP animals (that were transcardially perfused with $0.9 \%$ saline) and processed for Golgi-Cox staining according to a published protocol (Gibb \& Kolb, 1998). Briefly, brains were removed and immersed in Golgi-Cox solution ( $1: 1$ solution of $5 \%$ potassium dichromate and $5 \%$ mercuric chloride diluted 4:10 with $5 \%$ potassium chromate (Glaser \& Van der Loos, 1981) for 14 days; the brains were then transferred to a $30 \%$ sucrose solution (3 days) before being cut on a vibratome. Coronal sections ( $200 \mu \mathrm{m}$ thick) were collected in $6 \%$ sucrose and blotted dry onto gelatin-coated microscope slides. They were subsequently alkalinized in $18.7 \%$ ammonia, developed in Dektol (Kodak, Linda-Velha, Portugal), fixed in Kodak Rapid Fix (prepared to manufacturer's instructions), dehydrated through a graded series of ethanols and cleared in xylene before being mounted and cover slipped. Slides were coded before morphometric analysis in both sets.

\subsection{Dendritic tree analysis}

Three-dimensional reconstructions of representative Golgi-impregnated neurons from the dorsal hippocampus (sections between -2.52 and $-3.60 \mathrm{~mm}$ from bregma) were blindly performed for NP and LP offspring. The criteria used to select neurons for reconstruction were as follows: (i) full impregnation of the neurons along the entire length of the dendritic tree; (ii) dendrites without significant truncation of branches; (iii) relative isolation from neighboring impregnated neurons to avoid interference with the analysis; and (iv) no morphological changes attributable to incomplete dendritic impregnation of Golgi-Cox stain. For each selected neuron, all branches of the dendritic tree and the location of all dendritic spines were reconstructed at $600 \times$ magnification, using a motorized microscope (Carl Zeiss Axioplan 2, with oil immersion objectives), attached to a camera (DXC-390; Sony Co., Japan) and the Neurolucida software (MicroBrightField, VT, USA). Three-dimensional analysis of the reconstructed neurons was performed using NeuroExplorer software (MicroBrightField). For the dendritic analysis ( $N P=9, L P=9$ ), the hippocampus was divided into three areas CA1, CA3 and dentate gyros. For each region of the hippocampus five neurons out of a total of twenty neurons per region of each experimental group per animal were reconstructed. As a result in this study we have analyzed 120 neurons from the hippocampus. Two aspects of dendritic morphology were examined: dendritic length and number of dendritic intersections.

\subsection{Data presentation and statistical analysis}

The whole cognitive performance test and the structural study were performed and analyzed in a blinded fashion by different trained observers. All data are reported as mean \pm SEM. Data obtained over time were analyzed using appropriate ANOVA or Kruskal-Wallis one-way analysis of variance. Post hoc comparisons between selected means were made by Bonferroni's contrast test when initial ANOVA indicated statistical differences between experimental groups. Comparisons involving only two samples of independent observations tend within or between groups were made using the Student's $t$-test or Mann-Whitney $U$ test. A $P$ value $<0.05$ was considered to indicate significance.

\section{Results}

\subsection{Birth weight and brain weight}

The birth weight of the LP male pups was significantly reduced when compared to NP male pups ( $p \leq 0.0001)$. Ano-genital distance relative to body weight was significantly increased in the LP group. The weight of brains, corrected for total body weight, was not different in 16-wk old LP rats when compared to NP (Table 1). 
Table 1

Maternal dietary intake and birth weight, ano-genital distance and brain weight of maternal protein-restricted (LP-6\% casein) offspring compared to normal protein (NP-17\% casein) intake during pregnancy. Mean \pm SEM; $n$ refers to the number of litters. Statistically different when $p<0.05$.

\begin{tabular}{|c|c|c|c|}
\hline Parameters & Normal protein (NP) $(n=9)$ & Low protein $(\mathrm{LP})(n=9)$ & $P$ \\
\hline Maternal dietary intake (g) & $16.1 \pm 2.1$ & $18.5 \pm 2.7$ & $<0.001$ \\
\hline Birth weight $(\mathrm{g})$ & $6.5 \pm 0.06$ & $5.5 \pm 0.1$ & 0.0514 \\
\hline Ano-genital distance $(\mathrm{mm} / \mathrm{g})$ & $1.4 \pm 0.02$ & $1.5 \pm 0.02$ & 0.0075 \\
\hline Brain weight $(\mathrm{g})$ & $0.005 \pm 0.0001$ & $0.006 \pm 0.0001$ & 0.1 \\
\hline
\end{tabular}
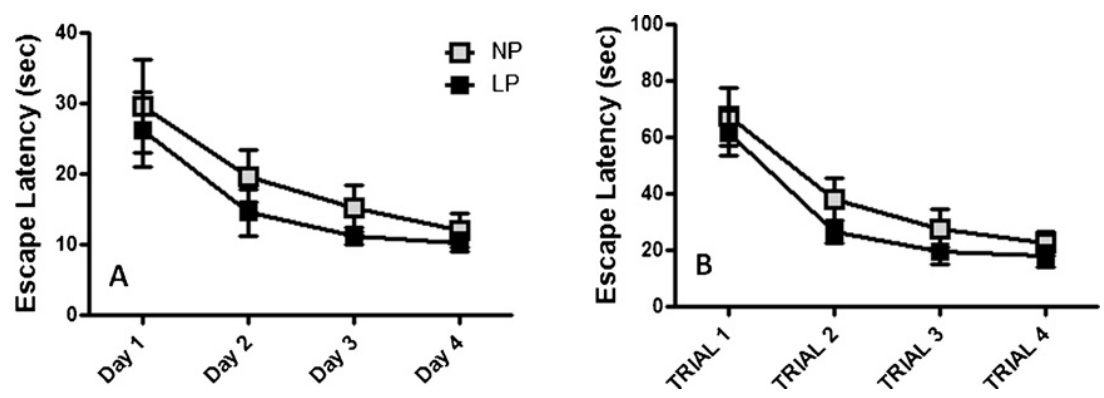

Fig. 1. Morris water maze training performance. (A) No differences in working memory between NP and LP groups. (B) No differences in reference memory between NP and LP groups. The graphics represent the number of quadrants traversed by the animal to find the platform.

\subsection{Behavior analysis - Morris water maze}

\subsubsection{Working memory}

For the working memory, ANOVA repeated-measures for escape latency showed no significant difference across our experimental groups $(F=1.21, p=0.28)$. A significant difference across days was found, suggestive of learning $(p=<0.0001$; Fig. 1A).

\subsubsection{Reference memory}

For the reference memory, repeated-measures ANOVA for escape latency showed no changes in the LP group when compared to NP animals ( $F=0.76, p=0.39)$. Again, both groups learned the task across the days ( $p=<0.0001$; Fig. 1B).

\subsection{Dendritic tree analysis}

We analyzed the apical and basal dendrites of CA1, CA3 and dentate gyrus of NP and LP animals. We found no significant differences between the groups in the length of basal and apical dendrites of CA1 neurons (NP, $1450 \pm 101.9$ vs. LP, $1638 \pm 99.52 p=0.1$; Fig. 2 A basal dendrites), (NP, $1024 \pm 77.9$ vs. LP, $1175 \pm 93.99 p=0.2$; Fig. $2 B$ apical dendrites).

In CA3 pyramidal neurons, we observed a significant decrease in the length of basal dendrites in the LP group (NP, $1265 \pm 102.3$ vs. LP, $920.5 \pm 72.49 p=0.01$; Fig. $3 \mathrm{~A}$ ), but no differences in apical dendrites (NP, $1621 \pm 131.8$ vs. LP, $1360 \pm 120.0 p=0.15$; Fig. 3B). Sholl analysis revealed a reduction of dendritic intersections (between 40 and $120 \mu \mathrm{m}$ from the perikarya) in LP when compared with that observed in NP (Fig. 3C). In granule neurons of the dentate gyrus, we did not observe any differences between groups (NP, $1841 \pm 146.2$ vs. LP, $1794 \pm 126.7 p=0.81$; Fig. 4).

\section{Discussion}

Evidence supports the assertion that disturbances during critical periods of fetal development may determinate permanent structural and functional alterations in organs and systems and predispose individuals to metabolic, cardiovascular and behavioral disorders later in life (Ashton, 2000; Barker, 1998; Lesage et al., 2006; O'Regan et al., 2004; Plagemann, 2004; Seckl and Meaney, 2004). Gestational psychological and nutritional stresses may be involved in fetal programming as shown in several experimental models (Persson and Jansson, 1992; Woodall et al., 1996; Godfrey et al., 1996; Langley-Evans et al., 1996; Mesquita et al., 2010a,b). As a result of this interest, a number of experimental studies have been developed to elucidate underlying biological mechanisms of programming.

The current study showed, in gestational protein-restricted offspring, a reduced birth weight of pups, which directly reflects the importance of proper protein intake during pregnancy for fetal growth and maturation. We also observed an increase of the anogenital distance in prenatal protein restricted male offspring. This data are in accordance with previous observations from us and other authors that maternal food restriction causes increased anogenital distance, which, in turn, is associated with enhanced levels of progesterone, corticosterone, estradiol and testosterone at 19 days of gestation in female and male offspring (Zambrano et al., 2005; Mesquita et al., 2010a,b).
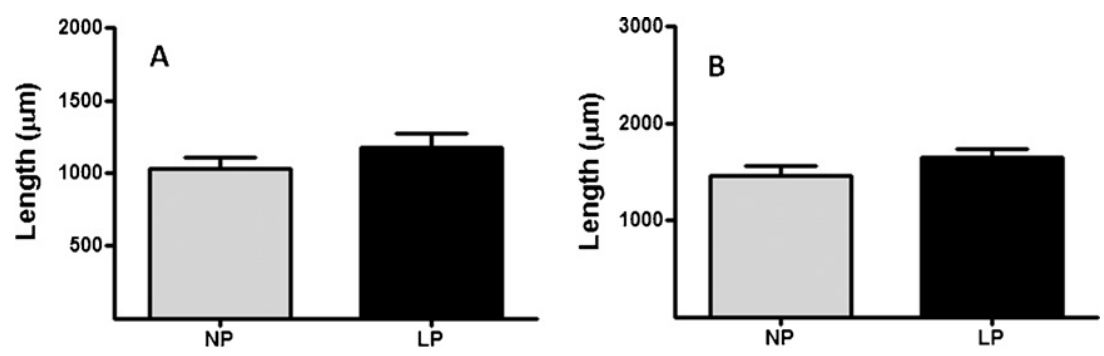

Fig. 2. Basal (A) and apical (B) dendritic length of CA1 neurons. 

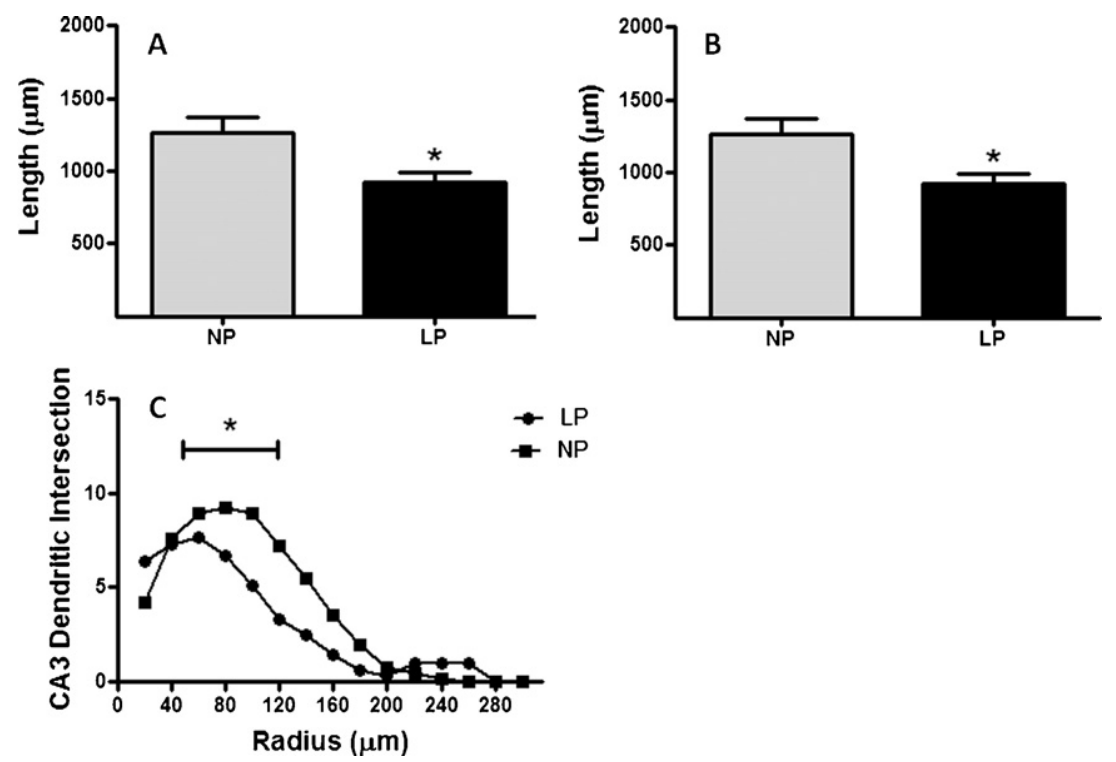

Fig. 3. Basal (A) and apical (B) dendritic length of CA3 neurons. The gestational protein restriction led to a decrease in the length of basal dendrites of neurons of the CA3 sub region of the dorsal hippocampus. By Sholl analysis we found a reduction of dendritic intersections (between 40 and $120 \mu \mathrm{m}$ from the perikarya) in LP when compared with that observed in NP $(C)$.

The dorsal hippocampus is a brain region related to emotion, memory and spatial learning. In information processing, DH is primarily involved in the cognitive process of learning and memory associated with navigation, exploration and locomotion, whereas the $\mathrm{VH}$ is the part of the temporal lobe associated with motivational and emotional behavior (Fanselow and Dong, 2010). Here, in maternal protein-deprived offspring model, we performed the MWM test to assess the DH related forms of learning and memory (Stewart and Morris, 1993). Several characteristics have contributed to the prevalent use of the MWM, including in this study, among which are the lack of required pretraining, its high reliability across a wide range of tank configurations and testing procedures, the extensive evidence of its validity as a measure of hippocampal-dependent spatial navigation and reference memory, its specificity as a measure of place learning and, its relative immunity to motivational differences across a range of experimental treatments (Morris, 1993; Vorhees and Williams, 2006). Thus, despite MWM capitalizing on this strength, in the current study, we did not found significant differences between cognitive process of learning and memory response in LP and NP offspring, suggesting that such functional process of $\mathrm{DH}$ were not altered by gestational protein restriction intake. Additionally, the spatial learning results, confirming previous study from (Tonkiss et al., 1994, 1997), has not shown any effect or impairment of performance in prenatal protein restricted offspring.

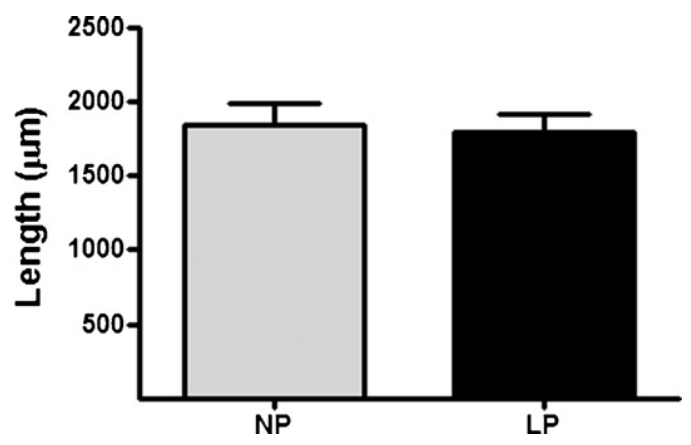

Fig. 4. Dendritic length of dentate gyrus neurons.
We may hypothesize that the timing of the maternal nutritional insult can differentially affect the development and function of neurons such as observed in other models where protein restriction starts five weeks before breeding. Neuroanatomical studies that have investigated the effects of prenatal malnutrition have found deficits such as loss of neurons (Lister et al., 2005) decrease of body size, length of apical dendrites and branching and spine density in the CA3 pyramidal cell layer (Díaz-Cintra et al., 1994). In CA1, it has been observed deficits in spine density of pyramidal cells in the stratum molecular (Cintra et al., 1997). On the dentate gyrus, these studies have found reductions in somatic axis and in the number of dendrites branching and spines (Cintra et al., 1990). In an attempt to analyze whether three-week gestational protein restriction might cause structural changes in the hippocampus, we carried out a detailed morphometric analysis of CA3 DH dendritic cytoarchitecture in Golgi-Cox stained preparations of adult male LP offspring. Although we have not noticed any change in the MWM tests assessing the DH learning and memory function, by applying 3-dimensional analysis of Golgi-Cox stained dorsal hippocampus, the current study have demonstrated significant decreases in the length of apical dendrites and in the branching and intersections of apical and basal dendrites of CA3 pyramidal neuron, in gestational protein-restricted offspring. On the other hand, the architecture of CA1 and dentate gyrus was unchanged. Taking into account the above data, the current study revealed a clear dissociation between behavioral test response and changes in hippocampus neurons changes as a consequence of fetal programming. The functional significance of dendritic remodeling in terms of absolute impact on hippocampus processing has remained elusive. Supporting our data showing no significant MWM score differences despite of reduced dendritic arborization in this pyramidal cell layer, recently, Koubeissi et al. (2011) have demonstrated that bilateral cuts of the CA3 dorsal hippocampus layer did not affect MWM scores in rats.

From a behavioral perspective, studies have been demonstrating that the CA3 region of the hippocampus plays an important role in the encoding of new spatial information within short-term memory with duration of seconds and minutes. This can easily be observed in tasks that require rapid encoding, novelty detection, working memory or recall trial, primarily, for spatial information. These are tasks that have been assumed to reflect the operations 
of episodic memory and require interactions between CA3 and the dentate gyrus via mossy fiber inputs. The output from CA3 via the fimbria and the medial and lateral perforant path plays a supporting role in the neural circuit for the operation of these tasks. The CA3 also supports sequential processing of information in cooperation with CA1 based on the Schaffer collateral output from CA3 to CA1. However, as well as observed in the current work, many authors have hypothesized that the atrophy observed in the dendrites of hippocampus neurons may be a compensatory response to protect the hippocampus from further damage (Ohl and Fuchs, 1999; McEwen, 2001; Bartolomucci et al., 2002; de Quervain et al., 2009).

Interestingly, although earlier studies have reported atrophy only in apical dendrites, our results indicate that fetal programming caused significant atrophy in basal dendrites of hippocampus CA3 pyramidal neurons. Vyas et al. (2002) showed that induced chronic immobilization stress decreases total dendritic length and number of branch points in both apical and basal dendrites of CA3 pyramidal cells. Although the underlying mechanisms are still unclear, the association between maternal undernutrition and hormonal dysfunction has been proposed to induce intrauterine fetal programming. Studies have demonstrated that gestational protein restriction leads to severe physiological and morphological changes in neurons (Huang et al., 2003; Hoffmann and Schmitt, 2004; Hermel et al., 2001; Feoli et al., 2006; de Lima et al., 2012), in addition to behavioral changes (de Oliveira, 1985; Riul et al., 1999) and delays in cognitive and intellectual functions (Barnes, 1976; Wainwright and Colombo, 2006). During normal pregnancy, the fetus is protected from the high maternal glucocorticoid (GC) levels by placental $11-\beta H S D 2$, which efficiently inactivates corticosterone to 11-dehydrocorticosterone in rodents. In the LP model, it has been demonstrated a decreased activity and expression of this placental enzyme and, as a consequence, there is an excessive exposure of fetuses to the maternal steroids (Benediktsson et al., 1993; Stewart et al., 1995; Langley-Evans et al., 1996; Langley-Evans, 1997). The excessive levels of fetal glucocorticoids can impair brain development and affect behavior later in life both in humans and animal models (Johnson et al., 1981; Uno et al., 1990, 1994; Szuran et al., 2000; Antonow-Schlorke et al., 2001; Matthews, 2001; Antonow-Schlorke et al., 2003; French et al., 2004; Karemaker et al., 2008; Weinstock, 2008; Seckl, 2008). Many studies have shown that both chronic exposure to stressors and pharmacological treatments (e.g. dexamethasone) induce atrophy of dendrites of CA3 pyramidal cells (Fuchs et al., 1995; Magariños and McEwen, 1995; Woolley et al., 1990). More specifically, structural changes in dorsal CA3 region have been reported as a neural consequence of chronic stress (Watanabe et al., 1992; Magariños et al., 1996; McEwen and Magariños, 1997; Lambert et al., 1998; Vyas et al., 2002; McLaughlin et al., 2009; Christian et al., 2011).

The adrenal steroid appears to be crucial in structural remodeling (McEwen, 1999) since repeated corticosterone administration induces retraction of apical dendrites in the CA3 subregion of the hippocampus in adult male rats. Mineralocorticoid receptors in the hippocampus mediate the enhancement of neurogenesis and differentiation of processes of cultured hippocampus neurons, whereas glucocorticoid receptors are involved in the suppression of their morphology (Fujioka et al., 2006). Repeated corticosterone administration induces retraction of apical dendrites in the CA3 sub region of the hippocampus in adult male rats (Woolley et al., 1990). Stress-induced CA3 dendritic retraction is prevented by steroid synthesis blocker (Magariños and McEwen, 1995).

In our model we have demonstrated enhanced plasmatic corticosterone levels in 16-wk-old LP programmed rats (data not published), thus we may hypothesize that higher steroid levels may be a striking factor involved in the structural remodeling of the hippocampus as observed herein. However, our study is not able to answer the question whether CA3 dendritic atrophy is related to in uteri underdevelopment or results from a postnatal adaptation to programmed physiology in adult life. Further time-course studies should be done to assess both the corticosterone levels and its action over hippocampus dendritic 3-dimentional analysis in embryos and early postnatal age of gestational protein restricted animals.

\section{References}

Antonow-Schlorke, I., Kuhn, B., Muller, T., Schubert, H., Sliwka, U., Nathanielsz, P.W., Schwab, M., 2001. Antenatal betamethasone treatment reduces synaptophysin immunoreactivity in presynaptic terminals in the fetal sheep brain. Neuroscience Letters 297, 147-150.

Antonow-Schlorke, I., Schwab, M., Li, C., Nathanielsz, P.W., 2003. Glucocorticoid exposure at the dose used clinically alters cytoskeletal proteins and presynaptic terminals in the fetal baboon brain. Journal of Physiology 547, 117-123.

Ashton, N., 2000. Perinatal development and adult blood pressure. Brazilian Journal of Medical and Biological Research 33, 731-740.

Bannerman, D.M., Rawlins, J.N., McHugh, S.B., Deacon, R.M., Yee, B.K., Bast, T., Zhang, W.N., Pothuizen, H.H., Feldon, J., 2004. Regional dissociations within the hippocampus-memory and anxiety. Neuroscience and Biobehavioral Reviews $28,273-283$.

Barker, D.J., 1998. In utero programming of chronic disease. Clinical Science 95 $115-128$.

Barnes, R.H., 1976. Dual role of environmental deprivation and malnutrition in retarding intellectual development. American Journal of Clinical Nutrition 29, 912-917.

Bartolomucci, A., de Biurrun, G., Czeh, B., van Kampen, M., Fuchs, E., 2002. Selective enhancement of spatial learning under chronic psychosocial stress. European Journal of Neuroscience 15, 1863-1866.

Benediktsson, R., Lindsay, R.S., Noble, J., Seckl, J.R., Edwards, C.R., 1993. Glucocorticoid exposure in utero: new model for adult hypertension. Lancet 34, 339-341.

Cintra, L., Granados, L., Aguilar, A., Kemper, T., DeBassio, W., Galler, J., Morgane, P., Durán, P., Díaz-Cintra, S., 1997. Effects of prenatal protein malnutrition on mossy fibers of the hippocampal formation in rats of four age groups. Hippocampus 7 , 184-191.

Cintra, A., Solfrini, V., Agnati, L.F., Gustafsson, J.A., Fuxe, K., 1990. Strongly glucocorticoid receptor immunoreactive neurons in the neonatal rat brain. Neuroreport $2,85-88$.

Christian, K.M., Miracle, A.D., Wellman, C.L., Nakazawa, K., 2011. Chronic stressinduced hippocampus dendritic retraction requires CA3 NMDA receptors. Neuroscience 17, 26-36.

de Lima, M.C., Scabora, J.E., Lopes, A., Mesquita, F.F., Torres, D., Boer, P.A., Gontijo, J.A., 2012. Early changes of hypothalamic angiotensin II receptors expression in gestational protein-restricted offspring: effect on water intake, blood pressure and renal sodium handling. Journal of the Renin-Angiotensin-Aldosterone System, http://dx.doi.org/10.1177/1470320312456328.

de Quervain, D.J., Aerni, A., Schelling, G., Roozendaal, B., 2009. Glucocorticoids and the regulation of memory in health and disease. Frontiers in Neuroendocrinology 30, 358-370.

de Oliveira, L.M., 1985. Malnutrition and environment: interaction effects upon animal behavior. Revista Chilena de Nutrición 13, 99-108.

Diáz-Cintra, S., Cintra, L., Galván, A., Aguilar, A., Kemper, T., Morgane, P.J., 1991. Effects of prenatal protein deprivation on postnatal development of granule cells in the fascia dentata. Journal of Comparative Neurology 310, 356-364.

Díaz-Cintra, S., García-Ruiz, M., Corkidi, G., Cintra, L., 1994. Effects of prenatal malnutrition and postnatal nutritional rehabilitation on CA3 hippocampal pyramidal cells in rats of four ages. Brain Research 662, 117-126.

Fanselow, M.S., Dong, H.W., 2010. Are the dorsal and ventral hippocampus functionally distinct structures? Neuron 65, 7-19.

Feoli, A.M., Siqueira, I.R., Almeida, L., Tramontina, A.C., Vanzella, C., Sbaraini, S., Schweigert, I.D., Netto, C.A., Perry, M.L., Gonçalves, C.A., 2006. Effects of protein malnutrition on oxidative status in rat brain. Nutrition 22, 160-165.

French, N.P., Hagan, R., Evans, S.F., Mullan, A., Newnham, J.P., 2004. Repeated antenatal corticosteroids: effects on cerebral palsy and childhood behavior. American Journal of Obstetrics and Gynecology 190, 588-595.

Fujioka, A., Fujioka, T., Ishida, Y., Maekawa, T., Nakamura, S., 2006. Differential effects of prenatal stress on the morphological maturation of hippocampus neurons. Neuroscience 141, 907-915.

Fuchs, E., Uno, H., Flügge, G., 1995. Chronic psychosocial stress induces morphological alterations in hippocampus pyramidal neurons of the tree shrew. Brain Research 673, 275-282.

Glaser, E.M., Van der Loos, H., 1981. Analysis of thick brain sections by obversereverse computer microscopy: application of a new, high clarity Golgi-Nissl stain. Journal of Neuroscience Methods 4, 117-125.

Gibb, R., Kolb, B., 1998. A method for vibratome sectioning of Golgi-Cox stained whole rat brain. Journal of Neuroscience Methods 31, 1-4

Godfrey, K., Robinson, S., Barker, D.J., Osmond, C., Cox, V., 1996. Maternal nutrition in early and late pregnancy in relation to placental and fetal growth. British Medical Journal 17, 410-414.

Hermel, E.E., Severino, G.S., Cecconello, A.L., Pereira, F.M., Sanvitto, G.L., Lucion, A.B., 2001. Neonatal handling and the expression of immunoreactivity to tyrosine 
hydroxylase in the hypothalamus of adult male rats. Brazilian Journal of Medical and Biological Research 34, 1191-1195.

Hoffmann, M., Schmitt, F., 2004. Cognitive impairment in isolated subtentorial stroke. Acta Neurologica Scandinavica 109, 14-24.

Huang, L.T., Lai, M.C., Wang, C.L., Wang, C.A., Yang, C.H., Hsieh, C.S., Liou, C.W., Yang S.N., 2003. Long-term effects of early-life malnutrition and status epilepticus assessment by spatial navigation and CREB (Serine-133) phosphorylation. Brain Research. Developmental Brain Research 145, 213-218.

Johnson, J.W., Mitzner, W., Beck, J.C., London, W.T., Sly, D.L., Lee, P.A., Khouzami, V.A., Cavalieri, R.L., 1981. Longterm effects of betamethasone on fetal development American Journal of Obstetrics and Gynecology 141, 1053-1064.

Karemaker, R., Kavelaars, A., Tersteeg-Kamperman, M., Baerts, W., Veen, S., Samsom, J.F., Visser, G.H., van, B.F., Heijnen, C.J., 2008. Neonatal dexamethasone treatment for chronic lung disease of prematurity alters the hypothalamuspituitary-adrenal axis and immune system activity at school age. Pediatrics 121 870-878.

Kesner, R.P., Gilbert, P.E., Wallenstein, G.V., 2000. Testing neural network models of memory with behavioral experiments. Current Opinion in Neurobiology 10 260-265.

Kesner, R.P., 2007. Behavioral functions of the CA3 subregion of the hippocampus. Learning and Memory 14, 771-781.

Koubeissi, M.Z., Rashid, S., Casadesus, G., Xu, K., Syed, T.U., Lüders, H., Durand, D., 2011. Transection of CA3 does not affect memory performance in rats. Epilepsy \& Behavior 21, 267-270.

Lambert, K.G., Buckelew, S.K., Staffiso-Sandoz, G., Gaffga, S., Carpenter, W., Fisher, J., Kinsley, C.H., 1998. Activity-stress induces atrophy of apical dendrites of hippocampus pyramidal neurons in male rats. Physiology and Behavior 65, 43-49.

Langley-Evans, S.C., Welham, S.J., Sherman, R.C., Jackson, A.A., 1996. Weanling rat exposed to maternal low-protein diets during discrete periods of gestation exhibit differing severity of hypertension. Clinical Science 91, 607-615.

Langley-Evans, S.C., 1997. Intrauterine programming of hypertension by glucocorticoids. Life Sciences 60, 1213-1221.

Lesage, J., Sebaai, N., Leonhardt, M., Dutriez-Casteloot, I., Breton, C., Deloof, S. Vieau, D., 2006. Perinatal maternal undernutrition programs the offspring hypothalamus-pituitary-adrenal (HPA) axis. Stress 9, 183-198.

Lister, J.P., Blatt, G.J., DeBassio, W.A., Kemper, T.L., Tonkiss, J., Galler, J.R., Rosene D.L., 2005. Effect of prenatal protein malnutrition on numbers of neurons in the principal cell layers of the adult rat hippocampal formation. Hippocampus 15 393-403.

Magariños, A.M., McEwen, B.S., 1995. Stress-induced atrophy of apical dendrites of hippocampus CA3c neurons: involvement of glucocorticoid secretion and excitatory amino acid receptors. Neuroscience 69, 89-98.

Magariños, A.M., McEwen, B.S., Flugge, G., Fuchs, E., 1996. Chronic psychosocial stress causes apical dendritic atrophy of hippocampus CA3 pyramidal neurons in subordinate tree shrews. Journal of Neuroscience 16, 534-3540.

Matthews, S.G., 2001. Antenatal glucocorticoids and the developing brain: mechanisms of action. Seminars in Neonatology 6, 309-317.

McEwen, B.S., Magariños, A.M., 1997. Stress effects on morphology and function of the hippocampus. Annals of the New York Academy of Sciences 821 271-284.

McEwen, B.S., 1999. Stress and hippocampus plasticity (Review). Annual Review of Neuroscience 22, 105-122.

McEwen, B.S., 2001. Plasticity of the hippocampus: adaptation to chronic stress and allostatic load. Annals of the New York Academy of Sciences 933, 265-277.

McLaughlin, K.J., Baran, S.E., Conrad, C.D., 2009. Chronic stress- and sex-specific neuromorphological and functional changes in limbic structures. Molecular Neurobiology 40, 166-182.

Mesquita, F.F., Gontijo, J.A.R., Boer, P.A., 2010a. Expression of renin-angiotensin system signalling compounds in maternal protein-restricted rats: effect on renal sodium excretion and blood pressure. Nephrology, Dialysis, Transplantation 25 380-388.

Mesquita, F.F., Gontijo, J.A.R., Boer, P.A., 2010b. Maternal undernutrition and the offspring kidney: from fetal to adult life. Brazilian Journal of Medical and Biological Research 43, 1010-1018.

Morris, R., 1984. Developments of a water-maze procedure for studying spatial learning in the rat. Journal of Neuroscience Methods 11, 47-60.
Morris, R.G.M., 1993. An attempt to dissociate 'spatial-mapping' and 'workingmemory' theories of hippocampal function. In: Seifert, W. (Ed.), Neurobiology of the Hippocampus. Academic Press, New York, pp. 405-432.

Ohl, F., Fuchs, E., 1999. Differential effects of chronic stress on memory processes in the tree shrew. Brain Research. Cognitive Brain Research 7, 379-387.

O'Regan, D., Kenyon, C.J., Seckl, J.R., Holmes, M.C., 2004. Glucocorticoid exposure in late gestation in the rat permanently programs gender-specific differences in adult cardiovascular and metabolic physiology. American Journal of Physiology - Endocrinology and Metabolism 287, 863-870.

Persson, E., Jansson, T., 1992. Low birth weight is associated with elevated adult blood pressure in the chronically catheterized guinea-pig. Acta Physiologica Scandinavica $145,195-196$.

Plagemann, A., 2004. 'Fetal programming' and 'functional teratogenesis': on epigenetic mechanisms and prevention of perinatally acquired lasting health risks. Journal of Perinatal Medicine 32, 297-305.

Riul, T.R., Carvalho, A.F., Almeida, P.S., De-Oliveira, L.M., Almeida, S.S., 1999. Ethological analysis of mother-pup interactions and other behavioral reactions in rats: effects of malnutrition and tactile stimulation of the pups. Brazilian Journal of Medical and Biological Research 32, 975-983.

Seckl, J.R., Meaney, M.J., 2004. Glucocorticoid programming. Annals of the New York Academy of Sciences 1032, 63-84.

Seckl, J.R., 2008. Glucocorticoids developmental programming and the risk of affective dysfunction. Progress in Brain Research 167, 17-34.

Stewart, C.A., Morris, R.G.M., 1993. The water maze. In: Sahgal, A. (Ed.), Behavioral Neuroscience, Volume I, A Practical Approach. IRL Press at Oxford University Press, Oxford, pp. 107-122.

Stewart, P.M., Whorwood, C.B., Mason, J.I., 1995. Type 211 beta-hydroxysteroid dehydrogenase in foetal and adult life. Journal of Steroid Biochemistry and Molecular Biology 55, 465-471.

Szuran, T.F., Pliska, V., Pokorny, J., Welzl, H., 2000. Prenatal stress in rats: effects on plasma corticosterone hippocampus glucocorticoid receptors, and maze performance. Physiology and Behavior 71, 353-362.

Tonkiss, J., Shultz, P., Galler, J.R., 1994. An analysis of spatial navigation in prenatally protein malnourished rats. Physiology and Behavior 55, 217-224.

Tonkiss, J., Shultz, P.L., Shumsky, J.S., Galler, J.R., 1997. Development of spatial navigation following prenatal cocaine and malnutrition in rats: lack of additive effects. Neurotoxicology and Teratology 19, 363-372.

Uno, $\mathrm{H}$., Lohmiller, L, Thieme, C., Kemnitz, JW., Engle, MJ., Roecker, E.B, Farrel, P.M., 1990. Brain damage induced by prenatal exposure to dexamethasone in fetal rhesus macaques. I. Hippocampus. Brain Research. Developmental Brain Research 53, 157-167.

Uno, H., Eisele, S., Sakai, A., Shelton, S., Baker, E., Dejesus, O., Holden, J., 1994. Neurotoxicity of glucocorticoids in the primate brain. Hormones and Behavior 28 , 336-348.

Vorhees, C.V., Williams, M.T., 2006. Morris water maze: procedures for assessing spatial and related forms of learning and memory. Nature Protocols 1, 848-858.

Vyas, A Mitra, R., Shankaranarayana Rao, B.S. Chattarji, S., 2002. Chronic stress induces contrasting patterns of dendritic remodeling in hippocampus and amygdaloid neurons. Journal of Neuroscience 22, 6810-6818.

Zambrano, E., Rodriguez-Gonzalez, G.L., Guzman, C., Garcia-Becerra, R., Boeck, L. Diaz, L., Menjivar, M., Larrea, F., Nathanielsz, P.W., 2005. A maternal low protein diet during pregnancy and lactation in the rat impairs male reproductive development. Journal of Physiology 563, 275-284.

Wainwright, P.E., Colombo, J., 2006. Nutrition and the development of cognitive functions: interpretation of behavioral studies in animals and human infants. American Journal of Clinical Nutrition 84, 961-970.

Watanabe, Y., Gould, E., McEwen, B.S., 1992. Stress induces atrophy of apical dendrites of hippocampus CA3 pyramidal neurons. Brain Research 588, 341-345.

Weinstock, M., 2008. The long-term behavioural consequences of prenatal stress. Neuroscience and Biobehavioral Reviews 32, 1073-1086.

Woodall, S.M., Johnston, B.M., Breier, B.H., Gluckman, P.D., 1996. Chronic maternal undernutrition in the rat leads to delayed postnatal growth and elevated blood pressure of offspring. Pediatric Research 40, 438-443.

Woolley, C.S., Gould, E., McEwen, B.S., 1990. Exposure to excess glucocorticoids alters dendritic morphology of adult hippocampus pyramidal neurons. Brain Research 531, 225-231. 